\title{
From imitation to collusion: a replication
}

\author{
Jörg Oechssler ${ }^{1} \cdot$ Alex Roomets $^{2} \cdot{\text { Stefan } \text { Roth }^{3}}^{3}$
}

Received: 4 October 2015/Accepted: 29 November 2015/Published online: 15 February 2016

(C) Economic Science Association 2016

\begin{abstract}
In oligopoly, imitating the most successful competitor yields very competitive outcomes. This theoretical prediction has been confirmed experimentally by a number of studies. A recent paper by Friedman et al. (J Econ Theory 155:185-205, 2015) qualifies those results in an interesting way: While they replicate the very competitive results for the first 25-50 periods, they show that when using a much longer time horizon of 1200 periods, results slowly turn to more and more collusive outcomes. We replicate their result for duopolies. However, with 4 firms, none of our oligopolies becomes permanently collusive. Instead, the average quantity always stays above the Cournot-Nash equilibrium quantity. Thus, it seems that "four remain many" even with 1200 periods.
\end{abstract}

Keywords Imitation · Experiment - Cournot oligopoly · Walrasian outcome

JEL Classification C91 $\cdot$ C72 $\cdot$ D74

Electronic supplementary material The online version of this article (doi:10.1007/s40881-015-0019-x) contains supplementary material, which is available to authorized users.

Jörg Oechssler

oechssler@uni-hd.de

Alex Roomets

roomets@gmail.com

Stefan Roth

stefan.roth@upf.edu

1 Department of Economics, University of Heidelberg, Bergheimer Str.58, 69115 Heidelberg, Germany

2 Franklin and Marshall College, Lancaster, PA, USA

3 Universitat Pompeu Fabra, Barcelona, Spain 


\section{Introduction}

Imitation, in some strategic settings, has been shown to have negative side effects for the players involved. Specifically, in oligopoly, imitating the most successful competitor yields very competitive outcomes and correspondingly low profits. This has been predicted theoretically by Vega-Redondo (1997) and confirmed experimentally by a number of studies (Huck et al. 1999; Offerman et al. 2002; Apesteguia et al. 2007, 2010; Bigoni and Fort 2013). A recent paper by Friedman et al. (2015) qualifies those results in an interesting way: While they replicate the very competitive results for the first 25-50 periods, they show that when using a much longer time horizon of 1200 periods, results slowly turn to more and more collusive outcomes.

Friedman et al. (2015) show this result for long-horizon duopolies and triopolies. Huck et al. (2004a) review results from a large number of short-horizon experiments and conclude that 4 firms are usually sufficient to prevent tacit collusion. An interesting question, then, is whether collusive outcomes come about in long-horizon markets with more than 3 firms. Furthermore, given the novelty of the long-horizon result, it is important to test its robustness.

This paper seeks to address these issues by looking at long-horizon markets with 2 and 4 firms, using linear demand curves. We succeed in replicating Friedman et al. (2015) result that duopolies eventually became fairly collusive. However, while we also replicate a downward trend in quantities for 4 firms, none of our 4 firm oligopolies becomes permanently collusive. The average quantity always stays above the Cournot-Nash equilibrium quantity. Thus, it seems that "four remain many," even with 1200 periods, in the sense that collusion is very difficult to achieve.

\section{Experimental design}

Our experimental design was based on the one by Friedman et al. (2015). In order to allow for a replication, several key elements of their environment were maintained. Like in their experiment, the total number of periods was 1200, the length of each period was $4 \mathrm{~s}$, the computer interface very closely resembled theirs, and subjects received the same feedback information. However, we used a Cournot market with linear demand and cost functions, in contrast to Friedman et al. (2015) who used a unit elastic demand function. We did this for two reasons. First, we wanted to make our experiment comparable to the bulk of the literature, which uses linear demand and cost functions (see, e.g., Huck et al. 1999; Apesteguia et al. 2007, 2010). Second, due to the profit functions used in Friedman et al. (2015), two of their benchmark cases (the joint profit maximizing output and the perfectly competitive Walrasian outcome) are on the boundary of the strategy space, which could have an effect. Replicating their duopoly treatment with a more standard profit function can thus be valuable. ${ }^{1}$

\footnotetext{
1 Friedman et al. (2015) point out correctly that their profit function is steeper around the Cournot-Nash equilibrium and thus provides more incentives for collusion. In the linear setting, however, firms lose $100 \%$ of their profit when moving to the Walrasian outcome. Thus, if we find convergence toward the Walrasian outcome, our results become stronger.
} 
A few further differences between their design and ours are that we do not rematch firms after 400 periods, we frame the exercise as being a market with multiple firms as opposed to using a neutral framing, and we have a fixed choice set across treatments as opposed to one scaled by the number of firms. These design differences were intended to allow for more direct comparisons with existing literature mentioned above. While the fixed matching should increase collusion, the remaining differences are more likely to reduce collusion. The net effect of these changes then is not clear, but our confirming result in the 2-firm treatment suggests that none of these differences are crucial.

Most importantly, we extend Friedman et al.'s (2015) experiment by studying a market with 4 firms. Depending on the treatment, we had either 2 or 4 symmetric firms in each market. Quantities could be chosen with a slider almost continuously between 0 and $100 .^{2}$ The demand side of the market was modeled with the computer buying all supplied units according to the inverse demand function

$$
p^{t}=\max \left\{100-Q^{t}, 0\right\}
$$

with $Q^{t}=\sum_{i \in I} q_{i}^{t}$ denoting total quantity in period $t$ and $I$ the set of firms. The cost function for each seller was simply $C\left(q_{i}^{t}\right)=q_{i}^{t}$. Hence, profits were $\pi_{i}^{t}=\left(p^{t}-1\right) q_{i}^{t}$.

In the stage game, the following benchmarks can be derived (see Table 1). In the 4-firm treatment with $I=\{1,2,3,4\}$, the unique Cournot-Nash equilibrium (CNE) is given by $q_{i}^{\mathrm{CNE}}=19.8, i \in I$. The corresponding price is $p^{\mathrm{CNE}}=20.8$. The symmetric joint profit maximizing (JPM) output is given by $q^{\mathrm{JPM}}=12.375, i \in I$ resulting in a price of $p^{\mathrm{JPM}}=50.5$. Finally, the perfect competitive Walrasian outcome, in the following PCW, is signified by $q_{i}^{N}=24.75, i \in I$ and a price of $p^{N}=1$.

The duopoly with $I=\{1,2\}$ yields following predictions. The price in the case of the $\mathrm{CNE}$ is $p^{\mathrm{CNE}}=34$ resulting from $q_{i}^{\mathrm{CNE}}=33, i \in I$. JPM is given by $q_{i}^{\mathrm{JPM}}=$ $24.75, i \in I$ and a price of $p^{\mathrm{JPM}}=50.5$. Finally the PCW is signified by $q_{i}^{\mathrm{PCW}}=$ 49.5, $i \in I$ and $p^{\mathrm{PCW}}=1$.

Like in Friedman et al. (2015), subjects were not told the profit function in order to generate a low information environment. Subjects were only told that they represented firms and that the market price was decreasing in total quantity. Furthermore, they were told that the profit depended only on the current period's quantity decisions of the subjects in their group and that the profit function did not change across time. ${ }^{3}$

After making his or her decision in each period, each subjects had access to information about his or her total earnings, the current period, the number of periods remaining, the amount of time left in the current period (in the form of a progress bar), and information related to the quantities chosen and the profits earned by all subjects in his or her group in the previous period. The information about the previous period was presented on a 2-dimensional plot (see the Supplementary Material), which again closely resembled the clever display used by Friedman et al.

\footnotetext{
2 The step size of the slider was 0.016 .

3 The instructions subjects received are shown in the Supplementary Material.
} 
Table 1 Theoretical benchmarks

\begin{tabular}{|c|c|c|c|c|c|c|c|c|}
\hline & \multicolumn{4}{|c|}{2 Firms } & \multicolumn{4}{|l|}{4 Firms } \\
\hline & $q_{i}$ & $Q$ & $p$ & $\pi_{i}$ & $q_{i}$ & $Q$ & $p$ & $\pi_{i}$ \\
\hline PCW & 49.5 & 99 & 1 & 0 & 24.75 & 99 & 1 & 0 \\
\hline CNE & 33 & 66 & 34 & 1089 & 19.8 & 79.2 & 20.8 & 392.04 \\
\hline JPM & 24.75 & 49.5 & 50.5 & 1225.13 & 12.375 & 49.5 & 50.5 & 612.56 \\
\hline
\end{tabular}

(2015). Quantity and profit pairs were plotted with quantity on the $x$-axis and profit on the $y$-axis. This allowed subjects to quickly identify the quantities and profits of other players and themselves (players were color-coded to help with differentiation). Subjects could choose a quantity for the current period by clicking anywhere on the plot. When clicking, the $x$ value of the cursor location would be updated as the current quantity choice. An empty box along the $x$-axis was used to show this current choice. This choice could be updated as often as desired until the end of the period.

The experiment was computerized using z-Tree (Fischbacher 2007). ${ }^{4}$ In order to squeeze so many periods into a short time, periods only lasted $4 \mathrm{~s}$ each. In order to implement such short periods, a pseudo-real-time experiment was used. ${ }^{5}$ The specific functionality allowed subjects to select a quantity using a slider at any time. Every $4 \mathrm{~s}$, the current quantities for each subject were recorded to determine a 1-period payoff, and this information (quantities and payoffs for each subject) was communicated to each player. Quantity changes within the 4-second window did not take effect and were not communicated to other subjects until the beginning of the next 4-second window. To allow subjects to familiarize themselves with the software, the first period lasted $10 \mathrm{~s}$.

The experiments were conducted in the experimental laboratory of the economics department of the University of Heidelberg. Subjects were recruited via ORSEE (Greiner 2015). Subjects were randomly allocated to computer terminals in the laboratory such that they could not infer with whom they would interact in a fixed group. In the 2-firm treatment, there was 1 session of 12 subjects, for a total of 6 observations ( 1 pair $=1$ statistically independent observation). In the 4-firm treatment, there were 2 sessions of 8 and 16 subjects, for a total of 24 subjects and 6 observations ( 1 group of 4 subjects $=1$ observation). Subjects participated in a single, 1200-period, Cournot oligopoly market in a session. Profits were denominated in 'Taler', and the exchange rate for euro $(€)(70,000: 1$ in the 2-firm

\footnotetext{
4 The fact that $\mathrm{z}$-Tree can be used to run experiments in almost continuous time has also been used by Bigoni et al. (2015).

5 The z-Tree program utilizes the "later $(t)$ repeat \{\} " command with $t$ being a fraction of a second. Each iteration counts down the time left in the period. When the countdown finishes, current quantities and profits for each firm are recorded and reported to the group. Individual quantities can be updated at any time during the countdown or can be left at the previous period's level. Other firms' changes are only reported at the end of each period.
} 
treatment, 20000:1 in the 4-firm treatment) was known. The average payoff was about $17.70 € .^{6}$ Experiments lasted less than $120 \mathrm{~min}$ including instruction time. Instructions (see the Supplementary Material) were written on paper and distributed at the beginning of each session.

\section{Results}

Like Friedman et al. (2015), we first consider the initial 25 periods (see Fig. 1). ${ }^{7}$ As in their experiment, and in most of the existing literature, median total quantities are very competitive and in almost all periods above the Nash equilibrium quantity (CNE). This holds for both the 2-firm and the 4-firm treatments, although the distribution of median quantities is significantly different from the CNE only for the 4-firm treatment (Wilcoxon signed-rank tests, taking each market as one observation, $p=0.028$ for 4 firms and $p=0.173$ for 2 firms $){ }^{8}$

Next, we turn to the evolution of median total quantities over all 1200 periods (see Fig. 2; see also Table 2 for mean quantities, prices, and profits). The left panel of Fig. 2 shows the median quantities in the 2-firm treatment. Median quantities significantly decrease over time in the first half of the experiment, ${ }^{9}$ just as those observed in Friedman et al. (2015). After 400 periods, median quantities are persistently between the CNE and the collusive JPM output. The mean quantity of 29.29 for the last 400 periods (listed in Table 2) is (weakly) significantly different from the CNE of 33 (Wilcoxon signed-rank test, $p=0.075$ ) and (weakly) significantly different from the JPM of 24.75 (Wilcoxon signed-rank test, $p=0.075)$.

This indicates that the results of Friedman et al. (2015) are robust to the specific functional form of the demand and cost functions, since we can replicate their results with more standard functional forms.

The right panel of Fig. 2 shows the median quantities in the 4-firm treatment. As in Friedman et al. (2015, Fig. 3), we observe a clear downward trend in quantities. However, in contrast to their study, the downward trend in our experiment comes to a halt after around 600 periods. ${ }^{10}$ More importantly, quantities almost always stay above the CNE. The mean quantity of 22.24 for the last 400 periods (listed in Table 2) is (weakly) significantly different from the CNE of 19.8 (Wilcoxon signedrank test, $p=0.075$ ) and significantly different from the PWC of 24.75 (Wilcoxon signed-rank test, $p=0.046)$. On the aggregate, there are no collusive tendencies in markets with 4 firms.

\footnotetext{
${ }^{6}$ We added a show-up fee of $€ 10$ after the earnings in the first session were unexpectedly low.

${ }^{7}$ We use median quantities in the figures because Friedman et al. (2015) do so as well. The Supplementary Material contains the corresponding figures with mean quantities. The Supplementary Material also shows the development of standard deviations within markets.

${ }^{8}$ All $p$ values in this paper refer to two-sided tests.

${ }^{9}$ OLS regressions of total quantity on period show no significant time trend for $t>600$ while there is a significant time trend for $t \leq 600$ ( $p=0.032$, robust standard errors, clustered by market)

${ }^{10}$ OLS regressions of total quantity on period show no significant time trend for $t>600$ while there is a significant $(p<0.01)$ time trend for $t \leq 600(p=0.022$, robust standard errors, clustered by market).
} 


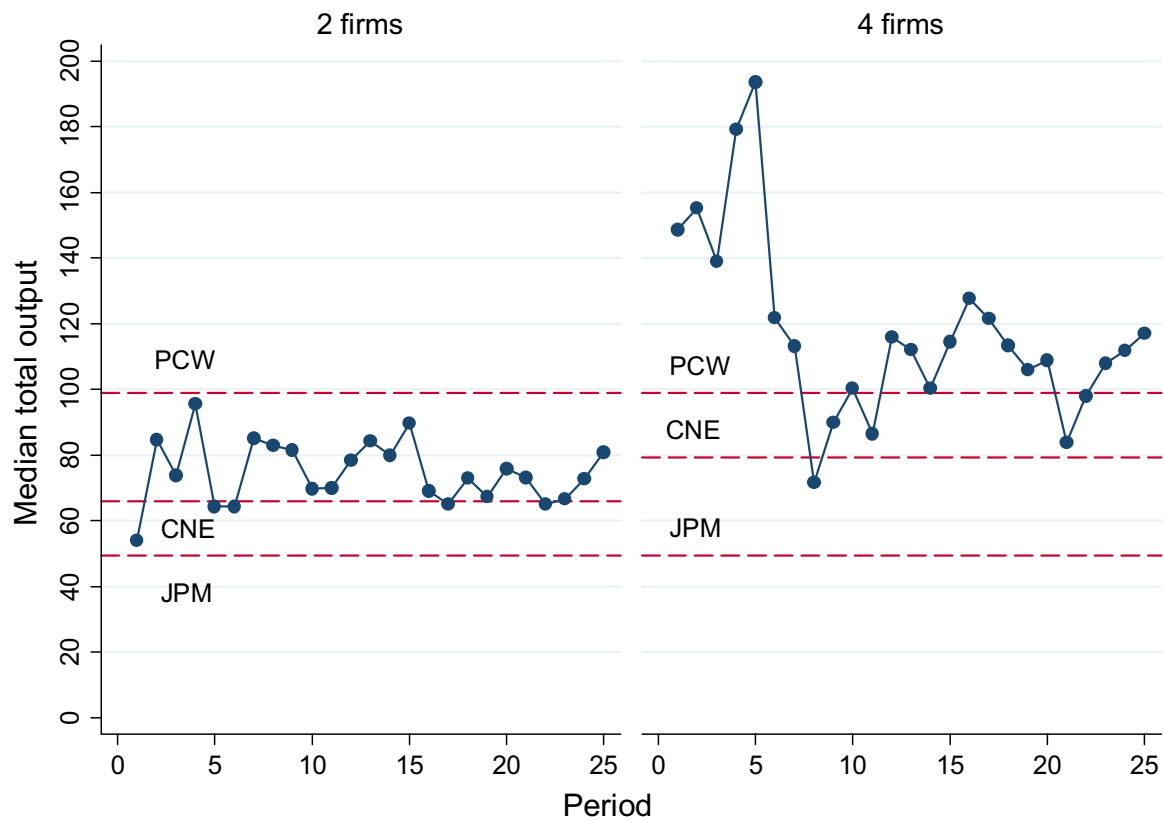

Fig. 1 Median quantities over the first 25 periods. Note medians are calculated for each period over all 6 markets

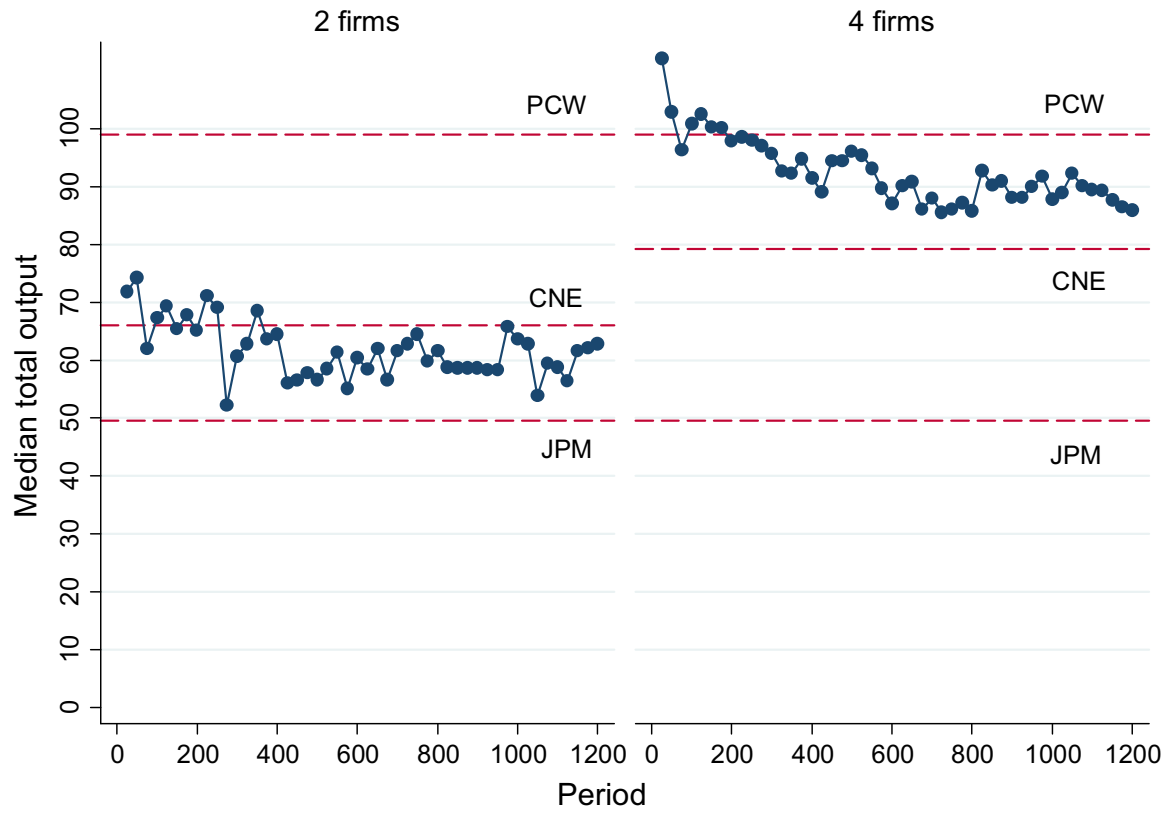

Fig. 2 Median quantities over all periods, plotted in bins of 25 periods. Note medians are calculated for each bin over all 6 markets and periods in the bin. 
Table 2 Mean quantities, prices, and profits

\begin{tabular}{|c|c|c|c|c|c|c|}
\hline \multirow[t]{2}{*}{ Periods } & \multicolumn{3}{|c|}{2 Firms } & \multicolumn{3}{|c|}{4 Firms } \\
\hline & $q_{i}$ & $p$ & $\pi_{i}$ & $q_{i}$ & $p$ & $\pi_{i}$ \\
\hline $1-50$ & 37.24 & 28.20 & 728.51 & 29.05 & 8.82 & 112.06 \\
\hline $1-400$ & 34.76 & 31.61 & 884.76 & 25.56 & 7.72 & 123.16 \\
\hline $401-800$ & 29.52 & 41.25 & 1098.26 & 22.75 & 11.86 & 204.67 \\
\hline $801-1200$ & 29.29 & 41.45 & 1134.60 & 22.24 & 12.35 & 221.79 \\
\hline $1151-1200$ & 30.88 & 38.40 & 1098.99 & 21.69 & 13.76 & 258.02 \\
\hline $1-1200$ & 31.19 & 38.11 & 1039.21 & 23.51 & 10.64 & 183.00 \\
\hline
\end{tabular}

3 5

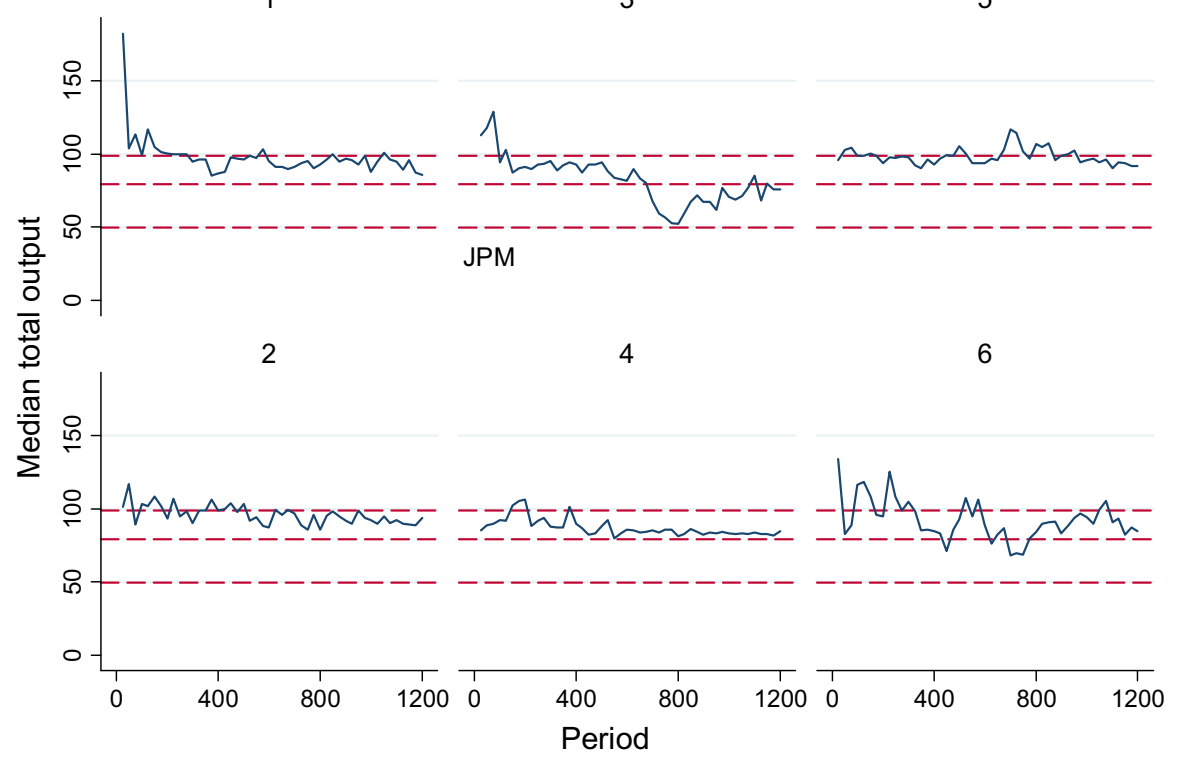

Graphs by market

Fig. 3 Median total output for the 6 individual markets in 4-firm treatment: Only market 3 ever comes close to the JPM

Indeed, looking at individual 4-firm market medians (see Fig. 3), we see that not one of the median quantities reaches the JPM permanently. Only one market (market 3) comes close at around period 800, but returns later to the CNE. While the JPM was not attained in any of the 4-firm markets, there seem to be cases of both the $\mathrm{CNE}$ and PCW. Markets 1, 2, and 5 never actually reach the CNE, and instead hover near the PCW, while firms in markets 3, 4, and 6 reach total output near the CNE for at least some periods. That said, of the markets that reached CNE levels of output, only market 4 seems to have spent much time there. Markets 3 and 6 were much more volatile. 
1

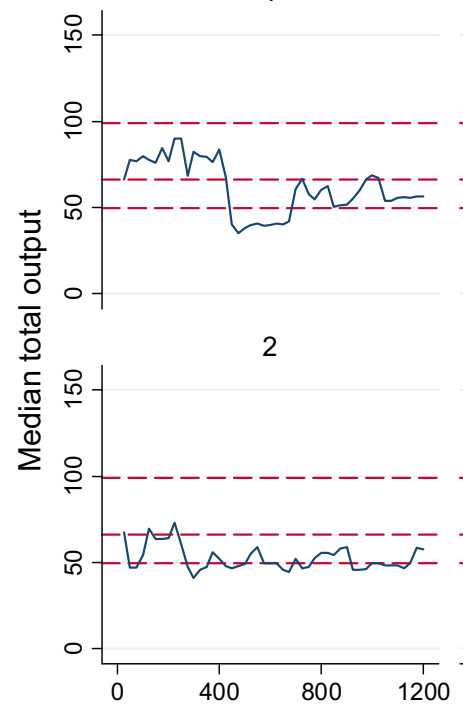

3

5

Graphs by market
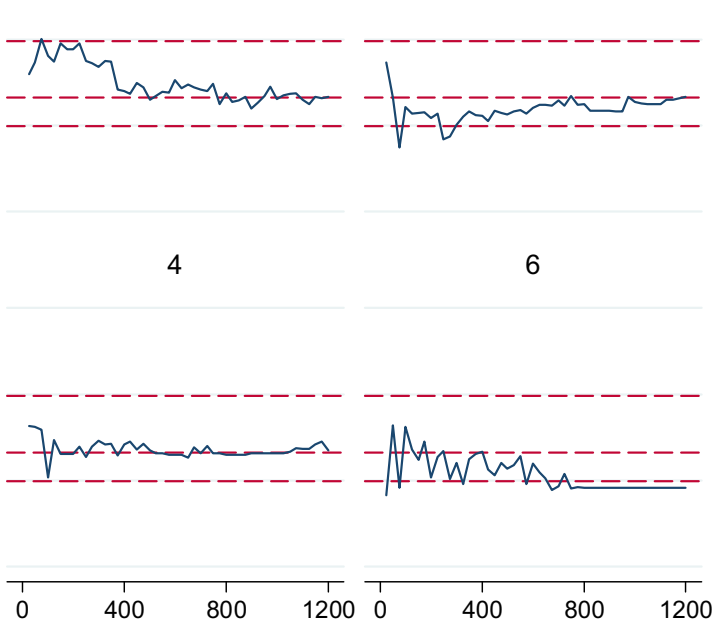

Period

Fig. 4 Median total output for the 6 individual markets in 2-firm treatment

This bimodality seen in the 4-firm markets can also be seen in the individual 2-firm medians (see Fig. 4). While in the 4-firm markets, we saw either the PCW or CNE, 2-firm markets tend toward either the CNE or the JPM. Markets 1, 2, and 6 were able to sustain the JPM, while markets 3, 4, and 5 settled near the CNE.

In both treatments, then, it seems that the individual market medians are distributed bimodally and, further, the 6-market median total output (from Fig. 2) is rarely observed in any particular market. It seems instead that the PCW, CNE, and JPM are somewhat focal and that the difference in treatments can largely be attributed to the number of markets drawn to each focal quantity. Mean figures in the Supplementary Material give further evidence of this bimodality.

\section{Conclusion}

Our experiment explores the robustness of the main result of Friedman et al. (2015). In Cournot duopoly markets, we confirm the presence of high levels of collusion after 1200 periods. However, when moving to markets with 4 firms, we find little difference from the existing literature. As predicted by theories of imitation, markets with 4 firms remain more competitive than the Cournot-Nash equilibrium even with 1200 periods. Our results, when added to those for 3-firm oligopolies in Friedman et al. (2015), suggest that the effect of increasing the number of periods quickly diminishes for markets with more firms. 
Further research is needed to explain the differing results with regard to the number of firms. The theoretical explanation given in Friedman et al. (2015), which is based on the trial \& error heuristic studied in Huck et al. (2003, 2004b), would also apply to our 4-firm treatment as well. Yet we found no indication that firms were successful in coordinating their movements toward the collusive outcome.

Acknowledgments We would like to thank Steffen Huck for helpful discussions. We also thank the editor and two anonymous referees for useful comments. The University of Heidelberg provided financial support for the experiments

\section{References}

Apesteguia, J., Huck, S., Oechssler, J., \& Weidenholzer, S. (2010). Imitation and the evolution of Walrasian behavior: Theoretically fragile but behaviorally robust. Journal of Economic Theory, 145, 1603-1617.

Apesteguia, J., Huck, S., \& Oechssler, J. (2007). Imitation-Theory and experimental evidence. Journal of Economic Theory, 136, 217-235.

Bigoni, M., \& Fort, M. (2013). Information and learning in oligopoly: An experiment. Games and Economic Behavior, 81, 192-214.

Bigoni, M., Casari, M., Skrzypacz, A., \& Spagnolo, G. (2015). Time horizon and cooperation in continuous time. Econometrica, 83, 587-616.

Fischbacher, U. (2007). z-Tree: Zurich toolbox for ready-made economic experiments. Experimental Economics, 10, 171-178.

Friedman, D., Huck, S., Oprea, R., \& Weidenholzer, S. (2015). From imitation to collusion: Long-run learning in a low-information environment. Journal of Economic Theory, 155, 185-205.

Greiner, B. (2015). Subject pool recruitment procedures: Organizing experiments with ORSEE. Journal of the Economic Science Association, 1(1), 114-125.

Huck, S., Normann, H.-T., \& Oechssler, J. (1999). Learning in Cournot oligopoly: An experiment. Economic Journal, 109, C80-C95.

Huck, S., Normann, H.-T., \& Oechssler, J. (2003). Zero-knowledge cooperation in dilemma games. Journal of Theoretical Biology, 220(1), 47-54.

Huck, S., Normann, H.-T., \& Oechssler, J. (2004a). Two are few and four are many: Number effects in experimental oligopoly. Journal of Economic Behavior and Organization, 53, 435-446.

Huck, S., Normann, H.-T., \& Oechssler, J. (2004b). Through trial and error to collusion. International Economic Review, 45(1), 205-224.

Offerman, T., Potters, J., \& Sonnemans, J. (2002). Imitation and belief learning in an oligopoly experiment. Review of Economic Studies, 69, 973-997.

Vega-Redondo, F. (1997). The evolution of Walrasian behavior. Econometrica, 65, 375-384. 